\title{
The Integration of Disability Content into Social Work Education: An Examination of Infused and Dedicated Models
}

\author{
Kristen Faye Bean \\ Taylor E. Krcek
}

\begin{abstract}
Disability content has been slowly integrated into social work curricula despite the large proportion of social workers supporting people with disabilities and its requirement in social work education by the Council on Social Work Education Educational Policy and Accreditation Standards. Schools of social work offer disability content to their students in three ways: infused, dedicated (specialization), or a combination of both. A content analysis of 1620 course titles and descriptions from the top schools of social work was conducted to assess the integration of disability content into social work curricula. Eighty percent of the schools included disability content in their curriculum. Disability content was more likely to be integrated using the infused rather than the dedicated model.
\end{abstract}

Keywords: Disability, disabilities, infused, curriculum, diversity

Disability content is important to social work education because social workers often serve people with disabilities and are required to advocate for vulnerable populations (National Association of Social Workers, 2006). Families of individuals with disabilities are often stressed, and are overrepresented in poverty statistics (DeNavas-Walt, Proctor, \& Smith, 2011; Neely-Barnes \& Dia, 2008). The oppression of this vulnerable population and the intersection of individual ability and social constraints surrounding disability issues justify social work's role in disability issues and service provision. The Council on Social Work Education (CSWE) 2008 Educational Policy and Accreditation Standards (EPAS) mandate that social work programs teach disability issues, which are included under mandates for education on diversity. In addition, the Council on Social Work Education requires disability content in social work education for accreditation (2008).

Social work researchers have assessed educational content in social work by conducting content analyses of course descriptions and syllabi (Julia \& Kondrat, 2000; Lacasse \& Gomory, 2003; Laws et al., 2010; Steen \& Mathiesen, 2005). These studies have each included a selection of a sample of courses and/or syllabi to analyze based on the identified research question in the study and the authors identified search terms or topics for the courses and/or syllabi. Findings from these studies have revealed whether information is included in social work courses and the number of times a subject is covered in social work courses. Findings from these studies have led to improvement in social work education by elucidating areas of social work education which were not covered adequately.

Previous research has found that only $27 \%-37 \%$ of schools of social work included disability content in their curriculum (Laws, Parish, Scheyett, \& Egan, 2010; Quinn, 1995). It is not only important to assess if disability content is included in social work education, but how it is included. The way in which disability content is included in curricula may impact its effectiveness in preparing social work students to

Kristen Faye Bean, MSW, Ph.D., is an Assistant Professor in the Department of Social Work at the University of Hawaii at Manoa. Taylor Krcek, MSW, is a doctoral student at the University of Tennessee in Knoxville, KY.

Copyright (C) 2012 Advances in Social Work Vol. 13 No. 3 (Fall 2012), 633-647 
work with people with disabilities. There are benefits and challenges to including disability content in dedicated or infused models throughout the social work curriculum. The current study conducted a content analysis of social work course titles and descriptions $(n=1620)$ of 25 schools of social work to assess the prevalence of disability content and use of the infused and dedicated models of integrating disability content into social work education.

\section{LITERATURE REVIEW}

\section{Importance of Disability in Social Work Education}

Disability is a familiar social problem in the United States. Census Bureau statistics indicate that $29 \%$ of U.S. families have one or more members with a disability (2005). Social workers provide many services to people with disabilities and their families. Worldwide, social workers are engaged in service, policy, and research endeavors which are aimed at garnering rights for individuals with disabilities (DeWeaver, 1995). The National Association of Social Workers (NASW) reports that social workers provide community-based housing, employment and training, education, medical, and psychological services for people with disabilities. The NASW concurrently found that a high proportion of social workers reported working with people with chronic medical (88\%), neurological (80\%), physical (79\%), and developmental (75\%) disabilities (National Association of Social Workers, 2006). Because of the high proportion of social workers who report working with individuals with disabilities, disability content is an exceptionally important component of social work education. This importance was emphasized in 2002 when the Council on Social Work Education (CSWE) published a curriculum resource spurred by the acknowledgement of the lack of familiarity by social work educators on resources and models to guide disability education in social work (Gilson, DePoy, MacDuffie, \& Meyershon, 2002).

\section{Disability Content in Social Work Curricula}

Although the CSWE EPAS did not mandate disability content in social work education until 2001, the Americans with Disabilities Act (ADA), enacted in 1990, brought attention to disability issues in social work. The ADA (1990) expanded the protection of people with disabilities from discrimination in employment and access in public areas. Quinn (1995) recognized the importance of social workers in providing services and advocating for people with disabilities after the enactment of the ADA. Quinn (1995) conducted a study of 93 schools of social work by reviewing their course titles and descriptions related to disability content and mailing a survey to the deans and directors of schools of social work inquiring about their number of students and faculty, faculty interest in disability and rehabilitation, and courses covering disability content. Of the 42 schools that responded to the survey, 81\% reported that they included specific content on disability in their curriculum, while the review of the course titles and descriptions found that $27 \%$ of schools of social work included disability content in their curriculum. A review of course titles and descriptions found that the majority of disability content was covered in practice courses (29\%), policy courses (18\%) and human behavior in the social environment courses (11\%). Quinn (1995) found that the only courses dedicated solely to disability content were policy courses. 
Since the CSWE EPAS in 2001 and 2008 mandated disability content in social work curricula, there has been one study that assessed curricula for content on developmental disabilities. Laws and colleagues (2010) conducted an internet-based review of the curricula of top-50 schools of social work based on the U.S. News and World Report rankings. Course information was analyzed to see if courses covered broad discussion of disability or developmental disability issues, specific interventions for people with developmental disabilities, or policies associated with people with developmental disabilities. Faculty expertise or interest in disability issues was also analyzed.

Laws and colleagues (2010) found that $37 \%$ of the reviewed schools included at least one course that covered a broad discussion of disability content. Twelve of the schools (24\%) offered courses that concentrated on disability related issues. Fiftyeight percent of the reviewed schools had at least one tenure-line faculty member with a research background in developmental disability studies or services. Although these findings contribute to the understanding of disability content in social work curricula, the authors' primary focus on developmental disabilities is a limitation. More information is needed on social work curricula and the spectrum of disabilities.

\section{Contrasting Infused and Dedicated Models of Disability Education}

Schools of social work offer disability content to their students in three ways: infused, dedicated (specialization), or a combination of both (Gourdine \& Sanders, 2003). The dedicated model of education includes a purposeful course designated to teach a topic, such as disability. An infused model spreads disability content across the courses within a curriculum (Knopf, 1996). Several studies have demonstrated the benefits of infused and dedicated education on disability content in preparing social work students to work with people with disabilities (Abrams \& Gibson, 2007; Begab, 1970; Cummings, Cassie, Galambos, \& Williams, 2006; Dyeson, 2004; Lee \& Waites, 2006; Mama, 2001; Nagda, et. al., 1999).

Some have proposed that the dedicated model is the preferred method of integrating diversity topics into social work curriculum (Begab, 1970; Mama, 2001; Nagda et. al., 1999). For example, a course utilizing the dedicated model might be an Advanced Field Practice course for BSW students, which purposefully addresses diversity issues in each class within the course (Mama, 2001). There are several benefits to this approach. The professor of a dedicated course often has expertise in the specific area being taught. Additionally, the professor of a dedicated course gains expertise in how to manage discussing diversity topics and has time to build the rapport with students needed to discuss these issues comfortably. Moore (2004) described the use of a course project on disability that was conducted throughout a course on generalist practice. Moore (2004) reported that students liked applying theories and course concepts to a project that would impact people with disabilities.

Others have proposed the use of the infused model (Abrams \& Gibson, 2007; Cummings et al., 2006; Dyeson, 2004; Lee \& Waites, 2006). Dyeson (2004) reported that, because education on diversity issues is infused throughout social work curricula, social workers gain an extensive education on these issues. In Gezinski's (2009) curriculum framework for LGBTQ content in social work, she argues for an infused model, positing that a holistic approach that examines the macro/micro and theoretical/practical is necessary for the integration of topics relating to oppressed 
groups. Within the infused model, diversity content permeates the CSWE's Educational Policy and Accreditation Standard's (EPAS) eight foundation curriculum content areas: values and ethics, diversity, economic justice, social work practice, policy, research, field education, and human behavior and social environment (HBSE) (Bergel, 2006). A benefit of the infused model is that most students taking courses in different concentration areas, such as direct practice or policy, will be exposed to diversity content in their classes.

\section{METHODS}

\section{Sample}

Course titles and descriptions $(n=1620)$ from the top-25 schools of social work (as ranked by the U.S. News and World Report in 2008) were collected in February 2010. Data were collected from both BSW and MSW programs. All schools had MSW programs, while only 13 had BSW programs. Data were also collected on both foundation/core and concentration/elective curricula, which were defined based on each school's classification. Course titles and descriptions were accessed through each institution's website. Schools were contacted via email if course titles and/or descriptions of the school's BSW and/or MSW curriculum were not available online. Four schools of social work had only course titles available. The course titles and any available course descriptions from these schools were used.

\section{Content Analysis}

Since 1952, when content analysis emigrated from mass communications research (Berelson, 1952), it has continued to be a methodology of choice for researchers not only within social work, but also psychology, history, anthropology, and other related fields, who are interested in making valid inferences from text. Content analysis can be defined as "a research technique for making replicable and valid inferences from data to their context" (Krippendorff, 2004, pp. 21).

This content analysis included unitizing, or distinguishing, segments of text that were of interest in the analysis (Krippendorff, 2004). Courses were coded by the first author. The second author coded a random sample of $10 \%$ of the courses separately to ensure inter-rater reliability. A Kappa of $.87(\mathrm{p}<.000)$ indicated almost perfect agreement among coders. Kappa is the most widely used measure of agreement (Orme \& Gillespie, 1986; Viera \& Garrett, 2005). Some studies which use Kappa to measure agreement experience a high percentage of agreement with corresponding low kappa values, which is known as the kappa paradox (Kuppens, Holden, Barker, \& Rosenberg, 2011). The current study did not experience this issue.

Courses were coded by level of education (BSW or MSW) and course type (Core/Foundation or Concentration/Elective). Other variables included "course title includes disability" and "course description includes disability". The unitizing of course titles and descriptions was guided by the following search terms: ability, ableism, developmental abnormalities, disabilities, disability, disabled, special needs, the exceptional child, special education, special needs, and handicapped. These terms, in either the course title or description, were used as indicators of disability content. The courses that included these terms were reviewed to be sure that the terms represented disability content. Four courses found in the search were not included in 
the study because they focused on "special needs" populations, such as elderly, rather than disability populations. Fifty-nine courses that included the term "ability" did not refer to clients' abilities. The majority of these courses referred to students' abilities. These courses were not included.

The main topic of the courses with disability content was assessed by whether or not the course included disability content in the title or not. If the course included disability content in the course title, then disability was the main topic of the course. If the course did not include disability content in the course title, then the course had a different main topic. Cross-tabulations were conducted between level of course (BSW or MSW) and the variables of "course title includes disability" and "course description includes disability content". Cross-tabulations were also conducted with course type and inclusion of disability content in either the course title or description. The course titles and descriptions with disability content were examined to assess the course type and disability type addressed in each course.

\section{RESULTS}

Twenty of the schools of social work (80\%) included disability content in course titles or descriptions in their curricula. Table 1 lists the 20 schools that included disability content in courses and the number of courses with disability content that each school offered. Among a total of 1620 courses from the top- 25 schools of social work, $109(7 \%)$ courses had disability related terms within the course title and/or course description. There were 22 BSW and MSW courses (1\%) with disability related terms in the course title. There were 87 courses (5\%) that included disability content within the course description. Only one out of 176 BSW courses had disability related terms within the course title and two (1\%) BSW course descriptions included disability content, indicating very low coverage of disability content in BSW programs. Out of 1444 MSW courses, 21 (1\%) had disability related terms within the course title and 85 (6\%) MSW course descriptions included disability content.

Eighty-seven (79.8\%) of the courses that included disability content reflected an infused approach. Of the 109 courses with disability content, there were 14 (12.8\%) foundation/core course descriptions with disability content, and none of the course titles of the foundation/core courses included disability content. Twenty-two (23.1\%) elective/concentration course titles included disability related terms, and seventythree (76.8\%) elective/concentration course descriptions included disability content.

Twenty-two (20.1\%) of the 109 courses' main topic was disability, which indicated the use of the dedicated education model. The descriptions of the courses with a main topic of disability differed based on approach to teaching. Table 2 displays the course titles and descriptions with a main topic of disability. 
Table 1: The Number of Courses with Disability Content in Schools of Social Work

\begin{tabular}{lc}
\hline Schools of Social Work & n \\
\hline University of Michigan-Ann Arbor & 26 \\
Columbia University & 8 \\
Case Western Reserve University & 8 \\
University of Washington & 8 \\
Smith College & 8 \\
Boston College & 6 \\
University of Chicago & 6 \\
University of Texas-Austin & 5 \\
SUNY-Albany & 5 \\
University of Wisconsin-Madison & 4 \\
University of California-Berkeley & 4 \\
New York University & 4 \\
Washington State & 4 \\
Virginia Commonwealth University & 3 \\
University of California-Los Angeles & 2 \\
University of Maryland-Baltimore & 2 \\
University of Pennsylvania & 2 \\
University of Pittsburgh & 2 \\
University of North Carolina & 1 \\
University of Illinois at Chicago & 1 \\
\hline
\end{tabular}


Table 2:

\section{Dedicated Courses with Disability Content}

\section{Course Title}

Intervention Approaches

for Families with Children

Who Have Developmental

Disabilities

Social Work, Education,

and the Exceptional Child

Topics in Disability

Studies

Disability Issues:

Obstacles and Solution in

Today's World

\section{Course Description}

Provides the knowledge and skills needed for social work practice with families with children who have developmental disabilities. Focuses on the application of theoretical models and practice concepts for intervening with family systems, siblings, and parents. Provides an understanding of the impact of disability on the family unit, family coping skills, and current practice approaches to family support, empowerment, and self-advocacy. Emphasizes the development of assessment and intervention skills relevant to working with this specialty population.

Focuses on understanding the characteristics and the family and social context of the exceptional child, with an emphasis on educational settings. Discusses practice approaches for working with exceptional children and their families. Includes an overview of legislation and policies pertaining to exceptional children. Emphasizes assessing children, working with them and their families to maximize social and educational potential, and supporting individual children in the school setting.

An Interdisciplinary approach to disability studies, including focus on the arts and humanities, natural and social sciences, and professional schools. Some topics include history and cultural representation of disability, advocacy, health, rehabilitation, built environment, independent living, public policy. Team taught with visiting speakers. Accessible classroom with realtime captioning.

This course will examine the topic of disability from various perspectives, including the historical development of civil rights, the legal framework, the medical model, and how disability is viewed across various cultures. It will examine different types of disabilities, how people with disabilities are treated and denied equal access to programs and employment, and what political/legal recourse is available to address these inequities. The course will also review progress that has been made in the United States regarding the integration of people with disabilities by removing attitudinal and architectural, barriers that they face in daily life. The course will also address how to interact with individuals who have disabilities, the differences between visible and non-visible disabilities, and how disability can affect individuals depending on whether they are children, teenagers or adults. Issues pertaining to dimensions of diversity (e.g., ability, age, class, color, culture, ethnicity, family structure, gender [including gender identity and gender expression], marital status, national origin, race, religion or spirituality, sex, and sexual orientation) will be given special attention, particularly in areas of policy development and service delivery for people with disabilities. 
The Exceptional Child

Disability: Medical,

Ethical, and Psychosocial Issues

Health, Mental Health, and Disabilities: Issues,

Policies, Research, and Programs

Empowerment Practice with Persons with

Disabilities

Social Work and Disabilities
This course focuses on categories of exceptional children as defined by federal and state legislation, including the Individuals with disability Education Act (P.L. 94-142), the Rehabilitation Act (Section 504), and policies and programs for children who have disabilities. The prevalence and description of childhood disabilities and chronic illnesses are discussed. The role of the social worker in providing appropriate services to children and their parents in a school setting is emphasized. Methods of evaluating children as well as current research in the field are considered.

This course examines a broad range of topics relating to disability and society. We will study traditional medical models of illness as well as social and minority paradigm models that arose from the disability rights movement. We will examine the impact of disability throughout the lifespan, review theories of adaptation, and discuss clinical practice concerns/interventions. Participants will have opportunities to study specific disabilities that interest them within the framework of the course. Social policy, disability-related entitlements, and recent legislation also will be covered, along with controversial disability ethics concerns such as physician-assisted suicide and health care rationing.

This course takes a problem-identification and problem-solving approach to the delivery of social work services in health, mental health, and disabilities, with content about the social policies and organization structures that characterize our current health-care system.

This course is designed to provide students with a background in theories and models of support involving people with developmental disabilities and their families, across the lifespan and across practice settings. Emphasis is given to understanding disability as a characteristic that is experienced on a spectrum as a natural part of the human condition and as a socially constructed category through which people experience discrimination and oppression. Emphasis is also given to promoting personal empowerment in service planning and upon exploring how the disability civil rights movement has influenced current social work best practice.

This course will consider disability policy, laws, history, and major current issues. We will consider theoretical models for considering disability from both individual and societal frameworks. Practice models will include the development of competence at each stage of the social work processes, and will focus especially on communication, access and barriers, resources, and current programs. Disability identity theory will offer a framework for understanding the wide variations among clients with disabilities in relation to their disability. We will study various broad types of disabilities, such as sensory impairments, cognitive impairments, developmental disabilities, mental illness, mobility impairments, and others as students interests suggest. We will consider the effect of disability at different periods of an individual's life - from disabilities which are inherited or manifested in infancy or early childhood through disabilities which occur in the later years. 
Social Work and Developmental

Disabilities

Health, Aging, and Disability Policy and

Services

Developmenta

Disabilities

Comparative Perspectives

on Disability and

Disability Policy
Definition, incidence, etiology, and prevention of mental retardation and other developmental disabilities. Examines the lifecycle needs of this population, as well as social-welfare issues, social services available, and the social worker's role. P: Jr st, soc work/welfare major.

Provides knowledge about the contemporary organization of health care, as well as policies and services for older adults and people with disabilities.

This course enhances the students' ability to practice social work with and on behalf of people with developmental disabilities and their families. The course provides a base of knowledge about developmental disabilities and differences, their causes and characteristics. Students learn how disabilities and learning differences impact personal, familial,

educational, social, and economic dimensions for the individual, family and society, with attention to the person's special life cycle needs and characteristics. The course also emphasizes legislative, programmatic, political, economic, and theoretica formulations fundamental to service delivery.

This course introduces students to social work with persons with disabilities and their families. We will consider the history, social construction, cultural perspectives, and demographics of physical, emotional, sensory, and cognitive disability. Major national disability policies and programs are studied and critiqued, along with individual and collective strategies that foster empowerment and social justice. Individual experiences of people with various types of disabilities and families are explored, followed by a discussion of issues of discrimination, equal access, universal design, and social integration. After gaining a sense of the personal experiences and social status of people with disabilities, implications for social work practice are addressed. 
Thirty-four (31.2\%) of the courses with disability related content specified a disability type that would be covered in the course. The courses described that they covered the following disabilities: 11 psychiatric (32.3\%), 10 childhood (29.4\%), 9 developmental (26.4\%), 5 physical (14.7\%), and 1 learning disabilities (3\%). Examples of courses that included developmental disability content referred to developmental delay or mental retardation in course descriptions. Reference to the "exceptional child", which is a reference to elementary school or middle school students with disabilities, is an example of childhood disability in a course. Psychiatric disability refers to courses that specified experiencing a disabling condition due to a mental illness. Courses with physical disability content usually mentioned "physical disability or handicap" within the course description. An example of a learning disability is a course that referred to "learning handicaps." Only one course description reported content on the ADA, while one other course reported content on the Individuals with Disabilities Education Act and the Rehabilitation Act, which are policies enacted prior to the ADA that affect people with disabilities.

\section{LIMITATIONS}

The sample in this study, the top 25 schools of social work, potentially represents model institutions for other schools of social work, which limits the generalizability of the findings. Green, Baskind, Fassler, and Jordan (2006) found that the U.S. News and World Report rankings were consistent with objective indicators of program success and representative of the perspective of deans and faculty members. Kirk's (1995) constructive critique of the U.S. News and World Report schools rankings showed that schools were ranked based on productivity, publications by professors at the school, and reputation, based on productivity and opinions of academics about the school. This indicates that the rankings may not be subjective, but that the top ranked schools are representative of schools that have good reputations from social work academics. Although this sample is not representative of the overall population of schools of social work, it does document how the top-ranking schools have integrated disability into curriculum. Since the sample is from the top-ranking schools, the results may represent schools with more disability content than the larger population of all schools of social work.

This study gathered information about curricula based on course titles and descriptions. Although previous studies assessing the impact of disability content in social work education have used similar methods, a review of syllabi, interviews with social work professors, or observations of social work courses would provide more information about social work curricula. This study can only conclude that the course titles and descriptions reported or did not report disability content. The results of this study provide information about the prevalence of disability content in social work curricula. This information is essential to have in order to ensure competency in disability service provision among social workers, which the NASW Code of Ethics mandates (2008). This data will also inform future research endeavors of disability content in social work education.

\section{DISCUSSION}

Eighty percent of the top-25 schools of social work included disability-related terms in their course titles and descriptions. Based on a review of course titles and descriptions, Quinn (1995) found that $27 \%$ of schools of social work included 
disability content in their curriculum prior to CSWE-EPAS mandate for social work schools to include disability content. Also, based on a review of course titles and descriptions, Laws et al. (2010) found that $37 \%$ of the top-50 schools of social work included developmental disability related content in curriculum. However, Laws and colleagues (2010) defined developmental disability-related content as "broad survey or discussion of intellectual and/or DD and disability issues” (p. 325). The present study shows a $53 \%$ increase in schools showing any disability content in course titles and descriptions since the CSWE-EPAS mandate to include disability content in social work curricula.

As measured by course descriptions available online, $80 \%$ of the top 25 schools of social work included disability content in their curriculum and disability content were present in elective courses more than foundation/core courses. Twenty percent of the courses with disability content used the dedicated model, while the remaining courses infused disability content into courses with other main topics. Only one course description mentioned covering the ADA. Developmental and childhood disabilities were reported the most often in the course titles and descriptions.

The majority of social work programs in this study infused disability content throughout many courses as indicated by course titles that did not include disabilityrelated terms. For example, a few of the infused course titles with disability content were: "Ethnicity and Social Welfare", "Social Work Practice in Health Care Settings", and "Clinical Practice in Schools". The heterogeneity of the titles of courses that include disability content indicates that schools of social work believe that different kinds of social workers, such as clinical and policy, should have knowledge of people with disabilities. Although social work has not yet defined a best practice of integrating disability content into curriculum, it appears that a large majority of schools believe that the infused approach is most appropriate for including disability content in curriculum.

While the overall inclusion of disability in social work curricula appears to have increased, it is especially important to analyze the content of the curriculum. Similar to Quinn (1995) who found only one course covering the ADA, this study also found only one course that included ADA in a course description and another course that included previously important policies that impact people with disabilities in a course description. In order for social workers to competently provide services for people with disabilities, it is critical that they understand the policy and law that affect many aspects of their lives, including housing, employment, and transportation.

This study examined the BSW and MSW programs at the top 25 schools of social work. Other studies have chosen to assess only MSW programs' integration of disability content (Begab, 1970; Quinn, 1995). While the sample of schools with BSW programs in this study was small $(n=13)$, it revealed that only a total of three courses within the BSW programs had disability content. BSW programs have been perceived as gatekeeping programs. Gatekeeping is used to assess a student's suitability for the social work profession. BSW programs use gatekeeping strategies, such as mandating a formal application into the BSW major before a student's junior year in college. The belief in social justice and knowledge of diversity issues are critical issues in assessing the suitability of BSW students to become professional social workers (Reynolds, 2004; Urwin, Van Soest, \& Kretzschmar, 2006). If disability content is not integrated into BSW curricula, then students may not have an 
opportunity become proficient in disability issues. A lack of inclusion of diversity issues, such as disability, in the social work curriculum could affect gatekeeping decisions.

\section{IMPLICATIONS FOR PRACTICE AND RESEARCH}

Almost one-third of U.S. families experience disabilities and issues related to those disabilities, including stress and poverty (DeNavas-Walt, Proctor \& Smith, 2011; Neely-Barnes \& Dia, 2008; U.S. Census Bureau, 2005). Not only are social workers mandated to receive education on disability content, people with disabilities and their families need social workers to be educated on issues impacting them, and, thus, provide appropriate services to meet their needs (Council on Social Work Education, 2008). While this study demonstrates an increase in disability content in social work curricula, it also shows that some schools of social work may not include any disability content in their curricula. This is concerning since social workers may graduate without basic knowledge of disability issues and may provide inadequate services for people with disabilities. For example, our study found that only one course description mentioned the ADA. While this policy protects people with disabilities from discrimination, it is dependent on self advocacy skills among people with disabilities (ADA, 1990). Many people with disabilities struggle with self advocacy; therefore, they need service providers to help them to understand and stand up for their rights (Downing, Earles-Vollrath, \& Schreiner, 2007; Gerber \& Price, 2003). If social workers themselves are not knowledgeable of the ADA, then they will not be able to help people with disabilities to advocate for their rights that are protected under the ADA.

This study's findings advance knowledge of disability content in social work education. It found that disability content was more likely to be infused in curricula rather than contained in dedicated courses; however, as mentioned previously, it is unknown whether infused or dedicated models of education are more effective. Future research should explore the effectiveness of integrating disability content using infused and dedicated models. Though the sample was small, this study was also the first to assess for disability content within BSW curricula. It found that very few BSW courses included disability content in their titles or descriptions. Because this is a first look at disability content in BSW programs, more research is needed that examines the amount and extent of disability and other diversity content within BSW curricula.

While this study assessed only course titles and descriptions for disability content, it was the only study that has assessed for content regarding all types of disabilities within social work curriculum since the enactment of the ADA (Quinn, 1995). The most recent assessment of disability content conducted by Laws and colleagues (2010) focused on developmental disability issues. Their study also analyzed course data that was present on the internet with similar methodology to this study. More information using a broader methodological approach, such as analysis of course syllabi, is still needed to fully assess the integration of disability content in social work education. 


\section{References}

Abrams, L. S., \& Gibson, P. (2007). Reframing multicultural education: Teaching white privilege in the social work curriculum. Journal of Social Work Education, 43(1), 147-160.

Americans with Disabilities Act of 1990, Pub. L. No. 101-336, 104 Stat. 327. (1990).

Begab, M. J. (1970). Impact of education on social work students' knowledge and attitudes about mental retardation. American Journal of Mental Deficiency, 74(6), 801-808.

Bergel, D. P. (2006). Baccalaureate social work education and courses on the aging: The disconnect. The Journal of Baccalaureate Social Work, 12(1), 105-118.

Berelson, B. (1952). Content analysis in communications research. New York: Free Press.

Cummings, S. M., Cassie, K. M., Galambos, C., \& Wilson, E. (2006). Impact of an infusion model on social work students' aging knowledge, attitudes, and interests. Journal of Gerontological Social Work, 47(3/4), 173-186.

Council on Social Work Education. (2008). Educational Practices and Accreditation Standards. Retrieved from http://www.cswe.org/Accreditation/Handbook.aspx

DeNavas-Walt, C., Proctor B. D., \& Smith, J. C. (2011). U.S. Census Bureau, Current Population Reports, P60-239, Income, Poverty, and Health Insurance Coverage in the United States: 2010. Washington, DC: U.S. Government Printing Office,

DeWeaver, K. L. (1995). Developmental disabilities: Definitions and policies. In R.

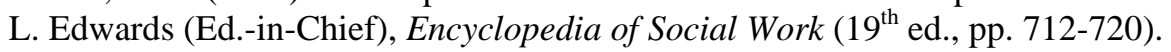
Washington, DC: NASW Press.

Downing, J. A., Earles-Vollrath, T., \& Schreiner, M. B. (2007). Effective selfadvocacy: What students and special educators need to know. Intervention in School and Clinic, 42(5), 300-204.

Dyeson, T. B. (2004). Cultural diversity and populations at risk: Social work education and practice. Social Work Perspective, 17(1), 45-47.

Gerber, P. J., \& Price, L. A. Persons with learning disabilities in the workplace: What we know so far in the Americans with Disabilities Act era. Learning Disabilities Research \& Practice, 18(2), 132-136.

Gezinski, L. (2009). Addressing sexual minority issues in social work education: A curriculum framework. Advances in Social Work, 10(1), 103-113.

Gilson, S. F., DePoy, E., MacDuffie, H., \& Meyershon, K. (Eds.). (2002). Integrating disability content in social work education: A curriculum resource. Alexandria, VA: CSWE.

Gourdine, R. M., \& Sanders, T. (2003). Missed opportunities and unlimited possibilities. Journal of Health and Social Policy, 16(1-2), 207-220.

Green, R. G., Baskind, F. R., Fassler, A., \& Jordan, A. (2006). The validity of the 2004 U.S. News and World Report's rankings of schools of social work. Social Work, 51(2), 135-145. 
Julia, M., \& Kondrat, M. E. (2000). Participatory action research and MSW curricula. Journal of Teaching in Social Work, 20(3/4), 101-124.

Kirk, S. (1995). School rankings: Mindless narcissism or do they tell us something? Journal of Social Work Education, 31(3), 408-415.

Knopf, N. P. (1996). Infusion content on older people with developmental disabilities in the curriculum. Journal of Social Work Education, 32(2), 215-226.

Krippendorff, K. (2004). Content analysis: An introduction to its methodology. Thousand Oaks, CA: Sage Publications.

Kuppens, S., Holden, G., Barker, H., \& Rosenberg, G. (2011). A Kappa-related decision: k, Y, G, or AC1. Social Work, 35(3), 185-189.

Lacasse, J., \& Gomory, T. (2003). Is graduate social work education promoting a critical approach to mental health practice? Journal of Social Work Education, 39(3), 383-408.

Laws, J., Parish, S., Scheyett, A., \& Egan, C. (2010). Preparation of social workers to support people with developmental disabilities. Journal of Teaching in Social Work, 30(3), 317-333.

Lee, E-K. O., \& Waites, C. E. (2006). Special section: Innovations in gerontological social work education infusing aging content across the curriculum: Innovations in baccalaureate social work education. Journal of Social Work Education, 42(1), 49-66.

Mama, R. S. (2001). Preparing social work students to work in culturally diverse settings. Social Work Education, 20(3), 373-382.

Moore, L. (2004). Opening doors to disability: A class project. Journal of Community Practice, 12(1/2), 89-105.

Nagda, B. A., Spearman, M. L., Holley, L. C., Harding, S., Balassone, M. L., MoiseSwanson, D., \& De Mello, S. (1999). Intergroup dialogues: An innovative approach to teaching about diversity and justice in social work programs. Journal of Social Work Education, 35(3), 433-449.

National Association of Social Workers. (2006). Assuring the Sufficiency of a Frontline Workforce: A National Study of Licensed Social Workers. Retrieved from http://workforce.socialworkers.org/studies/nasw 06 execsummary.pdf

National Association of Social Workers. (2008). Code of Ethics. Retrieved from http://www.naswdc.org/pubs/code/code.asp

Neely-Barnes, S. L., \& Dia, D. A. (2008). Families of children with disabilities: A review of research and recommendations for intervention. Journal of Early and Intensive Behavior Intervention, 5, 93-107.

Orme, J. G., \& Gillepsie, D. F. (1986). Reliability and bias in categorizing individual client problems. Social Service Review, 60(1), 161-174.

Quinn, P. (1995). Social work education and disability: Benefitting from the impact of the ADA. Journal of Teaching in Social Work, 12(1), 55-71. 
Reynolds, L. (2004). Gatekeeping prior to point of entry. Advances in Social Work, 5(1), 18-31.

Saleebey, D. (2006). The strengths perspective in social work practice $\left(4^{\text {th }}\right.$ ed.). New York: Pearson/Allyn and Bacon.

Steen, J. A., \& Mathiesen, S. (2005). Human rights education: Is social work behind the curve? Journal of Teaching in Social Work, 25(3), 143-156.

Urwin, C. A., Van Soest, D., \& Kretzschmar, J. A. (2006). Key principles for developing gatekeeping standards for working with students with problems. Journal of Teaching in Social Work, 26(1/2), 163-180.

U.S. Census Bureau. (2005). Disability and American Families: 2000. Census 2000 Special Reports. Retrieved from http://www.census.gov/prod/2005pubs/censr23.pdf

U.S. News and World Report. (2008). Rankings: Social Work. Retrieved from at http://rankings.usnews.com/best-graduate-schools/top-social-workschools/rankings

Viera, A. J., \& Garrett, J. M. (2005). Understanding interobserver agreement: The kappa statistic. Family Medicine, 37(5), 360-363.

\section{Author note:}

Address correspondence to: Kristen Faye Bean, PhD, Assistant Professor, School of Social Work, University of Hawaii at Manoa, 1800 East-West Road, Henke Hall, Rm. 224, Honolulu, HI. Email: socialworker2you@yahoo.com 